\title{
Evidence for Chlamydia pneumoniae of non-human origin
}

\author{
Christopher Storey,* Meryl Lusher, Peter Yates and Shirley Richmond \\ Division of Virology, Department of Pathological Sciences, The Medical School, University of Manchester, \\ Oxford Road, Manchester M13 9PT, UK
}

(Received 29 March 1993; revised 2 June 1993; accepted 14 June 1993)

\begin{abstract}
This paper describes the characterization and taxonomic status of N16, a chlamydial isolate from the respiratory tract of a horse. N16 contains plasmid DNA, has normal elementary body morphology and its inclusions do not stain with iodine. Its major outer-membrane protein (MOMP) gene was completely sequenced and compared with the MOMP genes of Chlamydia pneumoniae, $C$. psittaci, $C$. trachomatis and $C$. pecorum. This analysis revealed that N16 is closely related to the TWAR strain of $C$. pneumoniae $(94.5 \%$ and $94.4 \%$ DNA homology with TWAR isolates IOL-207 and AR-39 respectively). By comparison, N16 shows between $72 \cdot 1 \%$ and $73 \cdot 7 \%$ DNA homology with $C$. psittaci strains, $70.9 \%$ and $71 \cdot 1 \%$ homology with $C$. pecorum strains $L W 613$ and $1710 S$ and $69.2 \%$ homology with $C$. trachomatis serotype E. The MOMP gene of N16 shares $93.8 \%$ DNA homology with the MOMP gene of a chlamydial isolate $\mathrm{KC}$ from the conjunctiva of a koala. Monoclonal antibodies raised to $C$. pneumoniae IOL-207 and shown to be $C$. pneumoniae-specific confirmed that N16 was more closely related to $C$. pneumoniae than to $C$. psittaci. Thus DNA homology and monoclonal antibody data both suggest that horse chlamydiae, as exemplified by N16, form a new second strain of $C$. pneumoniae. This species is probably more widespread and diverse than the current literature would suggest.
\end{abstract}

\section{Introduction}

Chlamydiae are obligate intracellular bacteria that infect many mammalian and avian species, including man. Currently there are four species recognized: Chlamydia pneumoniae, C. psittaci, C. pecorum and C. trachomatis.

C. pneumoniae is a common respiratory pathogen of humans responsible for some outbreaks of communityacquired pneumonia (Grayston et al., 1989a). It was characterized as a new species (Grayston et al., 1989b) when shown to share $10 \%$ or less DNA homology with the other Chlamydia species. In addition, C. pneumoniae was shown to possess species-specific antigens that were recognized by monoclonal antibodies (mAbs). The infectious forms (elementary bodies; EBs) were said to have unique pear-shaped morphology. However it is now

*Author for correspondence. Tel. +44612755425 ; fax +4461275 5431.

Abbreviations: EB, elementary body; FAT, fluorescent antibody test; mAb, monoclonal antibody; MOMP, major outer-membrane protein; PCR, polymerase chain reaction.

The GenBank accession numbers for the MOMP gene sequences determined in this work are L04982 (N16), L04980 (N352) and X61096 (Fpn/pring). known that not all TWAR isolates have pear-shaped EBs (Carter et al., 1991; Popov et al., 1991). All isolates recognized in 1989 were from humans and they comprised a single strain that was called TWAR. None of these isolates contained plasmid DNA.

Relatively little is known about genetic variation amongst TWAR isolates. Studies of the major outermembrane protein (MOMP) gene, some portions of which exhibit a high level of variation in other chlamydiae, indicate that TWAR isolates are genetically similar. Thus a study of variable domain IV of the TWAR MOMP gene (Gaydos et al., 1992) found that all of the 13 isolates tested were identical, and the complete MOMP gene of two TWAR isolates, IOL-207 and AR39 , showed over $99 \%$ DNA sequence homology (Carter et al., 1991; Melgosa et al., 1991).

In contrast, $C$. psittaci is a diverse species which includes many pathogens of mammals and birds and, until recently, chlamydial isolates of non-human origin were usually considered to be $C$. psittaci. However it is now realized that some chlamydiae that infect ruminants are not closely related to other $C$. psittaci strains, and it has been proposed that they be classified as a separate species called C. pecorum (Fukushi \& Hirai, 1992). C. trachomatis is primarily a pathogen of humans although a strain which infects mice (mouse pneumonitis) was 
described by Nigg (1942). This strain is not closely related to other $C$. trachomatis strains although it is included in this species as it stains with iodine, the classic test used to distinguish $C$. trachomatis from $C$. psittaci. More recently a chlamydial isolate from pigs has also been described as $C$. trachomatis (Kaltenboeck et al., 1992).

In this paper we present evidence which suggests that $\mathrm{N} 16$, a chlamydial isolate recovered from the respiratory tract of a horse, belongs to the species $C$. pneumoniae. N16 was one of 15 isolates obtained during a survey of chlamydial infection in 300 horses (Mair \& Wills, 1992). When this isolate was investigated previously in our laboratory (Wills et al., 1990) it was classified as $C$. psittaci because inclusions did not stain with iodine. N16 was also shown to have normal EB morphology and to contain a $7.5 \mathrm{~kb}$ plasmid. It therefore did not conform to the species description of C. pneumoniae (Grayston et al., $1989 \mathrm{~b}$ ). However a comparison of the DNA sequence of the MOMP genes, and the reaction of mAbs to N16 and other isolates of $C$. pneumoniae and $C$. psittaci, now suggest N16 is a member of the species $C$. pneumoniae.

\section{Methods}

Strains. The following chlamydiae were used in this study: equine isolate N16 (Wills et al., 1990); C. pneumoniae IOL-207 (Dwyer et al., 1972); avian C. psittaci N352 isolated from a domestic duck (Richmond et al., 1982); feline C. psittaci Fpn/pring (Wills et al., 1984); avian $C$. psittaci 6BC (Morgan \& Wiseman, 1946); guinea-pig C. psittaci GPIC (Murray, 1964); C. trachomatis serotype E/T181 (Sompolinsky \& Richmond, 1974). All were cultured in McCoy cell monolayers by standard methods (Richmond et al., 1985).

DNA extraction, polymerase chain reaction $(P C R)$ and DNA sequence determination. Chlamydial EBs were harvested from McCoy cell monolayers infected with 10 inclusion-forming units per cell and

Table 1. Oligonucleotide primers used in PCR amplifications and sequencing reactions

\begin{tabular}{|c|c|c|}
\hline Primer & Sequence $5^{\prime}-3^{\prime}$ & $\begin{array}{l}\text { Position on } \\
\text { N16 sequence* }\end{array}$ \\
\hline spl & CAGGATATCTTGTCTGGC & -103 to -86 \\
\hline p2 & CTGATAACAAGGTGAGGA & 1206 to 1189 \\
\hline p3 & TTAAACATTTGGGATCG & 375 to 391 \\
\hline p4 & TCCCATAAAGCTCCACG & 599 to \\
\hline p5 & TGAGCAATGCGGATAG & 908 to \\
\hline p6 & CGTGGAGCTTTATGGGA & 583 to \\
\hline p7 & AGGTGCTTCAGGAGATC & 126 to \\
\hline $\mathrm{p} 8$ & CGATCCCAAATGTTTAA & 375 to \\
\hline p9 & CCAAGTAGCGCAAGGATC & 166 to \\
\hline plot & AGGCTGTTTTCACTTG & -154 to -139 \\
\hline pl1† & AGGTTCTGATAGCGGGACAA & 1256 to 1237 \\
\hline p12 & TGGCTGAGCAATGCGG & 912 to 897 \\
\hline
\end{tabular}

* A minus sign denotes upstream of the start codon.

† Primers pl0 and p11 were designed to hybridize to $C$. psittaci MOMP genes and the positions stated are for the N352 MOMP gene sequence. concentrated by centrifugation $(12000 \mathrm{~g}, 30 \mathrm{~min})$. The EBs were resuspended in $1 \mathrm{ml}$ water containing $250 \mu \mathrm{g}$ proteinase $\mathrm{K}$, incubated for $60 \mathrm{~min}$ at $56^{\circ} \mathrm{C}$ and then boiled for $15 \mathrm{~min}$. Ten microlitres of this extract contained sufficient chlamydial DNA for a single PCR reaction. Each PCR reaction contained $0.5 \mathrm{mM}$-dATP, $0.5 \mathrm{~mm}$-dCTP, $0.5 \mathrm{~mm}$ dGTP and $0.5 \mathrm{mM}-\mathrm{TTP}, 1$ unit Taq DNA polymerase (Boehringer Mannheim), $10 \mathrm{~mm}$-Tris/ $\mathrm{HCl} \mathrm{pH} 8 \cdot 8,4 \mathrm{~mm}-\mathrm{MgCl}_{2}, 50 \mathrm{~mm}-\mathrm{KCl}, 0.1 \%$ Triton X-100 and $0.2 \mu \mathrm{M}$ of each oligonucleotide primer pair. DNA was amplified by 30 cycles of $94^{\circ} \mathrm{C}$ for $2 \mathrm{~min}, 48^{\circ} \mathrm{C}$ for $1 \mathrm{~min}$ and $72^{\circ} \mathrm{C}$ for $1 \mathrm{~min}$. These conditions proved adequate for most combinations of primer pairs using $C$. pneumoniae or $C$. psittaci template DNA. The same oligonucleotide primers were used for PCR and DNA sequence determination (Table 1). PCR products were cloned directly into a PCR 1000 vector (Invitrogen Corp.) and inserts were then sequenced by the standard dideoxynucleotide chain-termination method (Sequenase, USB). All DNA sequences were determined in both directions, and from a minimum of three clones, to negate misincorporation errors produced by $T a q$ polymerase.

Sequence analysis. The following MOMP gene sequences were used for analysis: N16 (GenBank accession no. L04982); N352 (GenBank accession no. L04980); Fpn/pring (GenBank accession no. X61096); IOL-207 (GenBank accession no. M64064; Carter et al., 1991); $C$. pneumoniae AR-39 (GenBank accession no. M69230; Melgosa et al., 1991); GPIC (Zhang et al., 1989); ovine C. psittaci EAE/S26 (GenBank accession no. X51859; Herring et al., 1989); C. trachomatis L2 (GenBank accession no. M14738; Stephens et al., 1986); KC, LW613 and 1710S (Kaltenboeck et al., 1993). KC was isolated from the conjunctiva of a koala (Timms et al., 1988). LW613 and 1710S are both C. pecorum; LW613 was isolated from a cow and 1710S from a pig (Perez-Martinez \& Storz, 1985). (These three sequences were not complete as the first 132 bases and the last 39 bases were not determined; they were therefore 999 bases long. The sequences were kindly provided by Dr B. Kaltenboeck, Veterinaermedizinische Universitaet Wien, A-1030 Vienna, Austria.) DNA and amino acid sequences were analysed using the PCGENE suite of programs (IntelliGenetics Inc.). A dendrogram (Fig. 2) was constructed with the CLUSTAL program, which uses the method of unweighted pair group maximum averages (Sokal \& Sneath. 1963).

Fluorescent antibody test (FAT). Chlamydiae were cultured in McCoy cell monolayers grown on $10 \mathrm{~mm}$ glass coverslips. After incubation for $48 \mathrm{~h}$, monolayers were fixed for $10 \mathrm{~min}$ in either acetone or ethanol. Hybridoma supernatants containing mAbs $(200 \mu l)$ were added undiluted to the coverslips and incubated for $20 \mathrm{~min}$ at $37^{\circ} \mathrm{C}$. After washing in PBS (A) (Dulbecco's phosphate-buffered saline solution A), fluorescein-isothiocyanate-labelled anti-mouse immunoglobulins (Dako F261) diluted 1/50 in PBS(A) were added. After incubation at $37^{\circ} \mathrm{C}$ for $20 \mathrm{~min}$ the coverslips were washed in PBS(A) and mounted in $50 \%$ (v/v) glycerol in PBS(A). The coverslips were examined with $\times 25$ and $\times 63$ oil immersion objectives by epi-illumination.

mAbs. C. pneumoniae-specific mAbs were raised to 1OL-207 by standard methods (Harlow \& Lane, 1988). The antibodies were screened by FAT using whole inclusion antigens from $C$. pneumoniae IOL-207, C. psittaci 6BC, Fpn/pring and GPIC and C. trachomatis serotype E/T181. Only mAbs that gave bright inclusion fluorescence with IOL-207 but did not react to the other strains were designated C. pneumoniae-specific.

\section{Results}

The complete sequence of the MOMP gene of N16 was determined (Fig. 1) as were the complete DNA sequences of the MOMP genes of $C$. psittaci strains N352 (avian) 


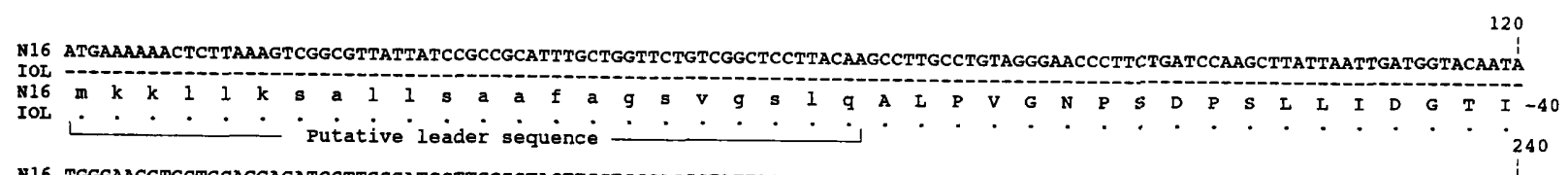

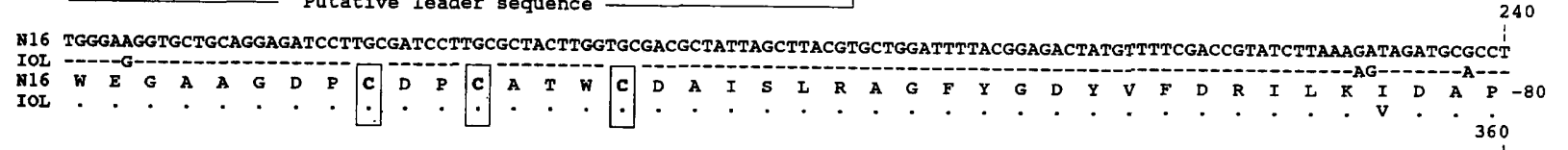

N16 AAAACATTTTCTATGGGAGCCAAACCTACAGGATCCGCTACTGCGAACTATACTACCGCCGTAGATAGACCTAATCCTGCCTACAATAAGCATTTATACGATGCAGAATGGTTCACTAAT IOL
N16
IOL

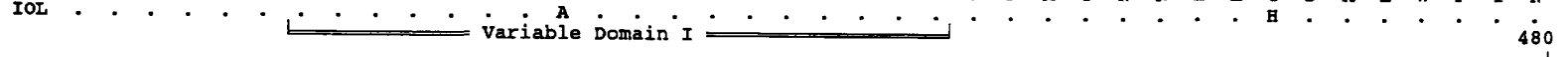

N16 GCAGGCTTCATTGCCTTAAACATTTGGGATCGCTTTGATGTTTTCTGTACCTTGGGAGCTTCTAATGGTTACGTTAAAGGAAACTCTGCGGCGTTCAATCTCGTTGGTTTATTCGGAGTT

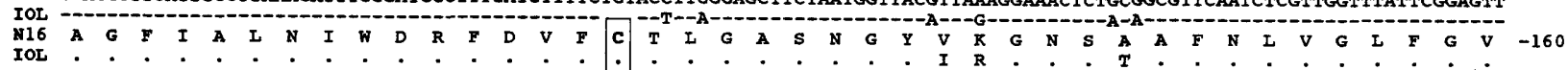

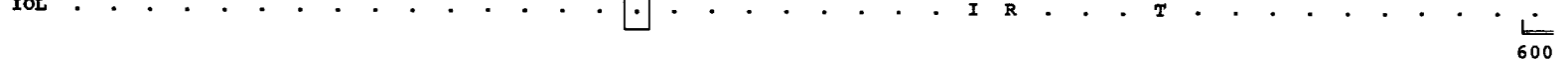
N16 AAAGTACTTCTGTAAATGCAAATGAACTACCAAACGTTTCTTTAAGTAATGGAGTTATCGAGCTCTATACAGATACTACTTTTGCTTGGAGCGTAGGTGCTCGTGGAGCTTTATGGGA

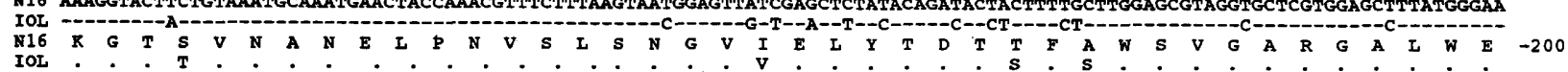
IOL $\cdot$. . T variabie Domain II N16 TGCGGTTGTGCCACTTTGGGaGCTGAATTCCAATATGCACAGTCTAAACCTAAAGTTGAagAaCtTAATGTGATCTGTAACGTATCGCAATTCTCTTTAAATAAACCCAAGGGCTATAÁ

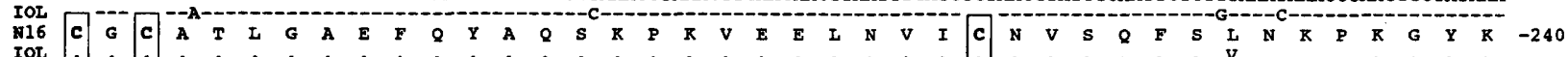

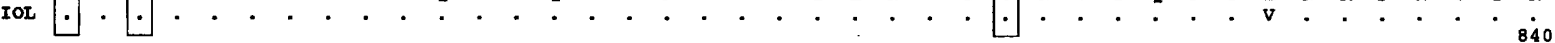
N16 GGCGTTGCTTTCCCTTTGCCAACAGATGCTGGCGTAGTAACAGCTGCTGGAACAAAGTCTGCGACCATCAATTATCATGAATGGCAGGTAGGAGCCTCTCTATCTTATAGACTCAACTCT

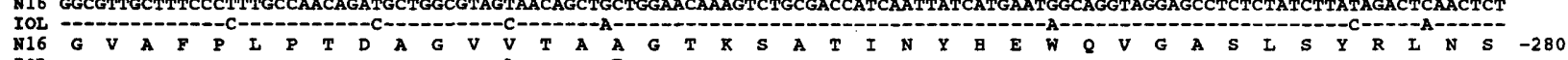

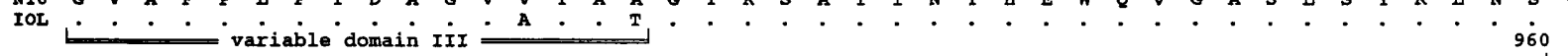

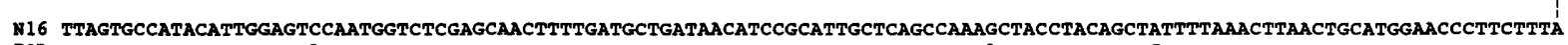

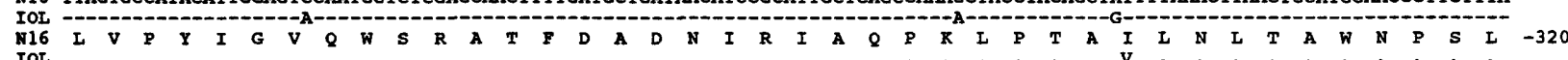

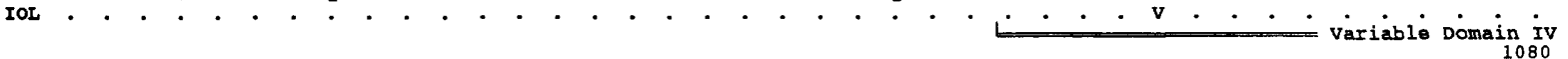
$\begin{array}{r}1080 \\ \text { ! } \\ \hline\end{array}$ N16 CTAGGGAGTGCCACAGCTGTTTCTTCATCTGATCAATTCTCAGATTTCATGCAGATTGTGTCCTGTCAAATCAACAAGTTTAAATCTAGAAGGCTTGTGGAGTTACTGTAGGAGCTACT

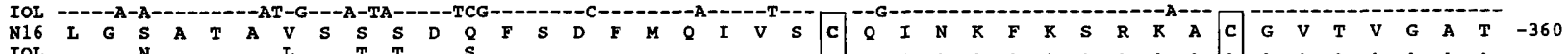
IOL

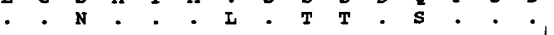

N16 TTAGTTGATGCTGATAAATGGTCACTTACTGCAGAAGCTCGTTTAATTAACGAGAGAGCTGCTCACATATCTGGTCAGTTCAGATTCTAA

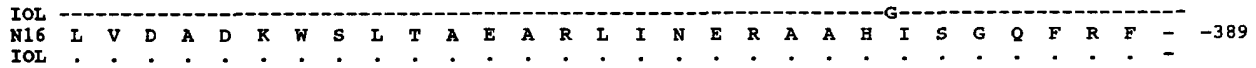

Fig. 1. DNA and deduced amino acid sequences of the MOMP gene of N16 are aligned with the sequences of $C$. pneumoniae IOL-207 (Carter et al., 1991). Identical nucleotides are shown as dashes and identical amino acids as dots. The cysteine residues are shown boxed and the variable domains are underlined.

and Fpn/pring (feline). (Sequences of N352 and Fpn/ pring are not shown but have been deposited in GenBank: see Methods for accession numbers.)

DNA and deduced amino acid sequences from all three strains exhibited salient features characteristic of chlamydial MOMPs described previously by Stephens $e t$ al. (1987), Herring et al. (1989), Zhang et al. (1989), Carter et al. (1991) and Melgosa et al. (1991). The distribution of cysteine residues found in N16 was identical to those previously described for $C$. pneumoniae IOL-207 and AR-39 (Carter et al., 1991; Melgosa et al., 1991) and included cysteine residues at positions 226 and 342 (Fig. 1) which have not been found in C. psittaci strains. A unique cysteine residue was found in Fpn/ pring at position 120 . The putative leader sequence of N16 was 22 amino acids long and identical to that of TWAR isolates IOL-207 and AR-39, whereas the putative leader sequences of Fpn/pring and N352 were 23 amino acids long and identical to those described previously for $C$. psittaci strains.

When the DNA sequence of the MOMP gene of N16 was aligned with that of TWAR IOL-207 (Fig. 1) a high degree of homology was evident, with only 64 bases different $(94.5 \%$ homology). The amino acid sequence homology was also very high, with only 18 differences between the two strains ( $94.9 \%$ amino acid homology), the majority occurring within the four variable domains. Six amino acid differences occurred within domain IV, which is the largest of the variable domains and is the proposed site of species and subspecies antigenic determinants (Baehr et al., 1988). This is in stark contrast to the lack of variation found in variable domain IV within TWAR isolates (Gaydos et al., 1992).

The percentage homology between N16, N352 (avian), 
Table 2. Percentage DNA sequence homology between chlamydial MOMP genes

\begin{tabular}{|c|c|c|c|c|c|c|c|c|c|c|}
\hline & $\mathrm{KC}$ & AR-39 & $\begin{array}{c}\text { IOL- } \\
207\end{array}$ & N352 & $\begin{array}{l}\text { Fpn/ } \\
\text { pring }\end{array}$ & GPIC & $\begin{array}{c}\text { EAE/ } \\
\text { S26 }\end{array}$ & LW613 & $1710 \mathrm{~S}$ & $\mathrm{Ct} \mathbf{L} 2$ \\
\hline $\begin{array}{l}\text { N16 } \\
\text { KC* } \\
\text { AR-39 } \\
\text { IOL-207 } \\
\text { N352 } \\
\text { Fpn/pring } \\
\text { GPIC } \\
\text { EAE/S26 } \\
\text { LW613* } \\
\text { 1710S* }\end{array}$ & 93.8 & $\begin{array}{l}94.4 \\
97.8\end{array}$ & $\begin{array}{r}94.5 \\
98.0 \\
99.7\end{array}$ & $\begin{array}{l}73 \cdot 7 \\
73 \cdot 7 \\
74 \cdot 9 \\
74 \cdot 8\end{array}$ & $\begin{array}{l}73 \cdot 7 \\
73 \cdot 0 \\
74 \cdot 1 \\
74 \cdot 0 \\
81 \cdot 5\end{array}$ & $\begin{array}{l}72 \cdot 4 \\
71 \cdot 7 \\
73 \cdot 2 \\
73 \cdot 1 \\
80 \cdot 8 \\
82 \cdot 3\end{array}$ & $\begin{array}{l}72 \cdot 1 \\
72 \cdot 0 \\
73 \cdot 0 \\
72 \cdot 9 \\
85 \cdot 6 \\
83 \cdot 4 \\
82 \cdot 2\end{array}$ & $\begin{array}{l}70 \cdot 9 \\
72 \cdot 2 \\
71 \cdot 8 \\
72 \cdot 0 \\
71 \cdot 0 \\
71 \cdot 8 \\
72 \cdot 5 \\
70 \cdot 2\end{array}$ & $\begin{array}{l}71 \cdot 1 \\
71 \cdot 8 \\
71 \cdot 8 \\
72 \cdot 0 \\
71 \cdot 5 \\
70 \cdot 8 \\
74 \cdot 0 \\
69 \cdot 0 \\
87 \cdot 8\end{array}$ & $\begin{array}{l}69 \cdot 2 \\
68 \cdot 6 \\
69 \cdot 1 \\
69 \cdot 1 \\
69 \cdot 3 \\
70 \cdot 1 \\
70 \cdot 1 \\
70 \cdot 5 \\
68 \cdot 8 \\
68 \cdot 0\end{array}$ \\
\hline
\end{tabular}

* Percentage homology values for KC, LW613 and 1710S are based on partial MOMP gene sequences.

Table 3. Reaction of $m A$ bs to chlamydial strains by FAT

\begin{tabular}{lcccc}
\hline \hline & \multicolumn{3}{c}{$\mathrm{mAb}$} \\
\cline { 2 - 5 } $\begin{array}{c}\text { Chlamydial } \\
\text { strain }\end{array}$ & $\mathrm{A1}$ & $\mathrm{A} 2$ & $\mathrm{~A} 3$ & $\mathrm{~A} 4$ \\
\hline N16 & + & + & - & - \\
IOL-207 & + & + & + & + \\
TW183 & + & + & + & + \\
6BC & - & - & - & - \\
Fpn/pring & - & - & - & - \\
GPIC & - & - & - & - \\
E/T181 & - & - & - & - \\
\hline
\end{tabular}

Fpn/pring (feline) and other chlamydial MOMP genes was determined (Table 2). The results show that N16 has a much higher homology to $C$. pneumoniae isolates IOL207 and AR-39 (94.5\% and $94.4 \%$ respectively) than to any of the $C$. psittaci, C. pecorum or C. trachomatis strains. In addition N16 has a high degree of homology to the koala isolate $\mathrm{KC}(93.8 \%)$. It is evident that N16, KC, IOL-207 and AR-39 form a distinct group sharing over $93 \%$ DNA homology. This group is quite distinct from $C$. psittaci or C. pecorum strains.

Studies using mAbs were consistent with the DNA homology results. mAbs A1-A4 raised against $C$. pneumoniae strain IOL-207 were shown to be $C$. pneumoniae-specific by testing them against $C$. pneumoniae isolates IOL-207 and TW-183 (reactivity against TW-183 was kindly assessed by Dr O. Caul, Public Health Laboratory Service, Bristol, UK, and Dr J. Treharne, Institute of Ophthalmology, London, UK), and strains of $C$. psittaci and $C$. trachomatis (Table 3). When N16 was tested against the four mAbs, A1 and A2 were reactive but $\mathrm{A} 3$ and $\mathrm{A} 4$ were not. This suggests that N16 and TWAR share some antigens that are recognized by $\mathrm{A} 1$ and $\mathrm{A} 2$ which are $C$. pneumoniae-specific. $\mathrm{A} 3$ and
A4 however recognize antigens that are apparently specific for the TWAR strain. None of the four mAbs reacted to chlamydial antigens in Western blotting experiments.

\section{Discussion}

Our results suggest that chlamydial isolate N16 is a member of the species $C$. pneumoniae and not $C$. psittaci as originally thought (Wills et al., 1990). The relationship of N16 to other chlamydiae, based on MOMP gene homology, is illustrated in a dendrogram (Fig. 2). This indicates that although $\mathrm{N} 16$ is on the $C$. pneumoniae branch it is quite distinct from the human TWAR strain.

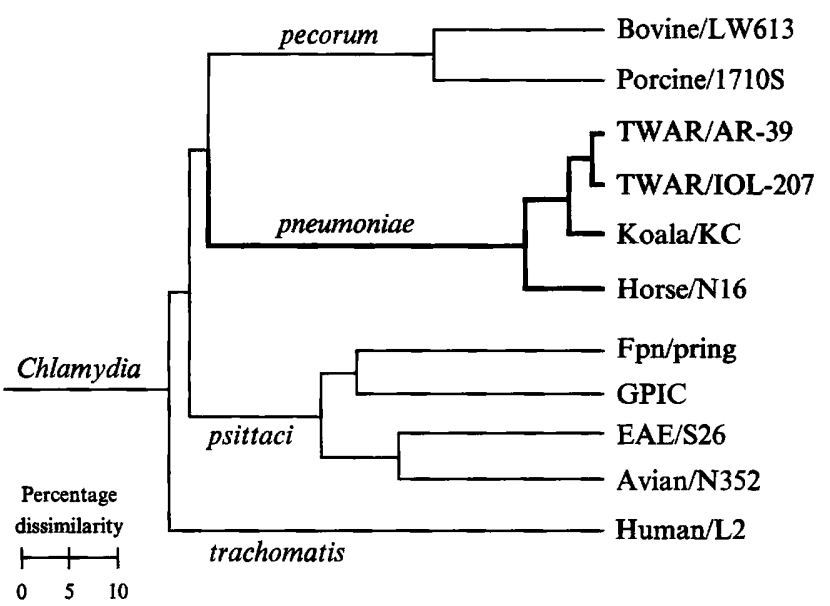

Fig. 2. Dendrogram to illustrate the relationships of chlamydiae based on the similarity of DNA sequences of the MOMP genes. The dendrogram was constructed using partial DNA sequences; the first 132 bases and the last 39 bases of each MOMP gene sequence were not used. This was done to enable all of the sequences to be aligned with the data available for chlamydial isolates KC, LW613 and 1710 S. 
The results obtained with $C$. pneumoniae-specific mAbs support our DNA homology comparisons. Other differences between N16 and TWAR are that N16 contains a plasmid and has normal EB morphology (Wills et al., 1990) whereas TWAR EBs were originally described as pear-shaped (Grayston et al., 1989b). However not all TWAR isolates have abnormal EB morphology (Carter et al., 1991; Popov et al., 1991) and the presence or absence of a plasmid is not a reliable indicator of species.

Studies on the plasmid of N16 (pCpnE) showed that it is similar in size $(7.5 \mathrm{~kb})$ and organization to the plasmids found in C. psittaci and C. trachomatis but that it has a unique restriction profile (Lusher et al., 1989). Preliminary DNA homology studies of the origin of replication and open reading frame 1 of $\mathrm{pCpnE}$ show that this plasmid is less closely related to the plasmids of C. psittaci strains N352, Fpn/pring and GPIC than these three plasmids are to each other (Yates et al., 1992).

The koala conjunctival isolate $\mathrm{KC}$ also appears to be C. pneumoniae and is, by MOMP DNA homology studies, more closely related to TWAR than N16 (Fig. 2). Kaltenboeck et al. (1993), in a study of the relationships of chlamydiae by homology of partial MOMP gene sequences, described this isolate as being $C$. pneumoniae-like. The $\mathrm{KC}$ isolate was obtained from the koala conjunctiva (Timms et al., 1988) and it appears to be quite different from chlamydial isolates obtained from the koala urogenital tract (Girjee et al., 1988).

The fact that $C$. pneumoniae-like organisms have now been recovered from three mammalian species that are not themselves closely related indicates that $C$. pneumoniae may be a more diverse and widespread species than the current literature suggests. It seems probable that $C$. pneumoniae of other mammals will be discovered. It is also possible that other $C$. pneumoniae isolates already exist in laboratory strain collections but, like $\mathrm{N} 16$ and $\mathrm{KC}$, have been wrongly described as C. psittaci.

We are grateful to Gill Mearns and Nichola Morrison for $\mathrm{mAb}$ production and characterization and to the North West Regional Health Authority, who provided a grant for this part of the study.

\section{References}

BaEHR, W., ZANG, Y. X., Joseph, T., SU, H. \& NaNo, F. E. (1988) Mapping antigenic domains expressed by Chlamydia trachomatis major outer membrane protein genes. Proceedings of the National Academy of Sciences of the United States of America 85, 4000-4004.

Carter, M. W., Al-Mahdawi, S. A. H., Giles, I. G., Treharne, J. D., Ward, M. E. \& Clarke, I. N. (1991). Nucleotide sequence and taxonomic value of the major outer membrane protein gene of Chlamydia pneumoniae IOL-207. Journal of General Microbiology 137, 465-475.

DWyer, R. St C., Treharne, J. D., Jones, B. R. \& Herring, J. (1972). Chlamydial infection. Results of microimmunofluorescence tests for the detection of type specific antibody in certain chlamydial infections. British Journal of Venereal Disease 48, 452-458.
Fukushi, H. \& HiraI, K. (1992). Proposal of Chlamydia pecorum sp. nov. for Chlamydia strains derived from ruminants. International Journal of Systematic Bacteriology 42, 306-308.

Gaydos, C. A., QutnN, T. C., Bobo, L. D. \& Eiden, J. J. (1992). Similarity of Chlamydia pneumoniae strains in the variable domain IV region of the major outer membrane protein gene. Infection and Immunity 60, 5319-5323.

Girjes, A. A., Hugall, A. F., Timms, P. \& Lavin, M. F. (1988). Two distinct forms of Chlamydia psittaci associated with disease and infertility in Phascolarctos cinnereus (Koala). Infection and Immunity 56, 1897-1900.

Grayston, J. T., Wang, S. P., Kuo, C. C. \& Campbell, L. A. (1989a). Current knowledge on Chlamydia pneumoniae, strain TWAR, an important cause of pneumonia and acute respiratory disease. European Journal of Clinical, Microbiological and Infectious Diseases 8, 191-202.

Grayston, J. T., Kuo, C. C., Campbell, L. A. \& Wang, S. P. (1989b). Chlamydia pneumoniae sp. nov. for Chlamydia strain TWAR. International Journal of Systematic Bacteriology 38, 265-268.

HaRlow, E. \& LANE, D. (1988). Antibodies: A Laboratory Manual. Cold Spring Harbor, NY: Cold Spring Harbor Laboratory.

Herring, A. J., Tan, T. W., Baxter, N. F., Inglis, N. F. \& Dunbar, S. (1989). Sequence analysis of the major outer membrane protein gene of an ovine abortion strain of Chlamydia psittaci. FEMS Microbiology Letters 65, 153-158.

Kaltenboeck, B., Koebl, O. \& Storz, J. (1992). Porcine chlamydiae include strains of Chlamydia psittaci and Chlamydia trachomatis. In Proceedings of the European Society for Chlamydial Research, vol. 2, p. 197. Edited by P.-A. Mardh, M. La Placa \& M. Ward. Uppsala, Sweden.

Kaltenboeck, B., Kousoulas, K. G. \& Storz, J. (1993). Structures of and allelic diversity and relationships among the major outer membrane protein (ompA) genes of the four chlamydial species. Journal of Bacteriology 175, 487-502.

LuSher, M., StOREY, C. C. \& RichmOND, S. J. (1989). Plasmid diversity within the genus Chlamydia. Journal of General Microbiology 135, 1145-1151.

MaIR, T. S. \& Wills, J. M. (1992). Chlamydia psittaci infection in horses: results of a prevalence survey and experimental challenge. Veterinary Record 130, 417-419.

Melgosa, M. P., Kuo, C. C. \& Campbell, L. A. (1991). Sequence analysis of the outer membrane protein gene of Chlamydia pneumoniae. Infection and Immunity 59, 2195-2199.

MoRGan, H. R. \& Wiseman, R. W. (1946). Growth of psittacosis virus in roller tube tissue culture; use in a vaccine. Journal of Infectious Diseases 79, 131-133.

MurRay, E. S. (1964). Guinea-pig inclusion conjunctivitis virus. 1. Identification as a member of the psittacosis-lymphogranulomatrachoma group. Journal of Infectious Diseases 114, 1-12.

NigG, C. (1942). Unidentified virus which produces pneumonia and systemic infection in mice. Science 95, 49-50.

Perez-Martinez, J. A. \& Storz, J. (1985). Antigenic diversity of Chlamydia psittaci of mammalian origin determined by microimmunofluorescence. Infection and Immunity 50, 905-910.

Popov, V. L., Shatkin, A. A., Pankratova, V. N., Smirnova, N. S., von Bonsdorff, C. H., Ekman, M. R., MortTinen, A. \& SaikKu, P. (1991). Ultrastructure of Chlamydia pneumoniae in cell culture. FEMS Microbiology Letters 84, 129-134.

Richmond, S. J., STIRLING, P. \& Ashley, C. R. (1982). Virus infecting the reticulate bodies of an avian strain of Chlamydia psittaci. FEMS Microbiology Letters 14, 31-36.

Richmond, S. J., Bailey, J. M. G., Bailey, A. S. \& Mearns, G. (1985). Primary isolation of Chlamydia trachomatis and Chlamydia psittaci in in vitro cell culture. In Isolation and Identification of Microorganisms of Medical and Veterinary Importance, pp. 297-312. Edited by C. H. Collins \& J. M. Grange. New York: Academic Press.

Sokal, R. R. \& SNEATH, P. H. A. (1963). Numerical Taxonomy. San Francisco: Freeman.

SOMPOLINSKY, D. \& RICHMOND, S. J. (1974). Growth of Chlamydia trachomatis in McCoy cells treated with cytochalasin B. Applied Microbiology 28, 912-914. 
Stephens, R. S., Mullenbach, G., Sanchez-Pescador, R. \& AgaBIAN, N. (1986). Sequence analysis of the major outer membrane protein gene from Chlamydia trachomatis serovar L2. Journal of Bacteriology 168, 1277-1282.

Stephens, R. S., Sanchez-Pescador, R., Wager, E. A., Inouye, C. \& URDEA, M.S. (1987). Diversity of Chlamydia trachomatis major outer membrane protein genes. Journal of Bacteriology 169, 3879-3885.

Timms, P., Eaves, F. W., Girjes, A. A. \& Lavin, M. F. (1988). Comparison of Chlamydia psittaci isolates by restriction endonuclease and DNA probe analysis. Infection and Immunity 56, 287-290.

Wills, J. M., GRUfFydd-Jones, T. J., Richmond, S. J. \& PAUL, I. D.
(1984). Isolation of Chlamydia psittaci from cases of conjunctivitis in a colony of cats. Veterinary Record 114, 344-346.

Wills, J. M., Watson, G., Lusher, M., WoOd, D. \& Richmond, S. J. (1990). Characterisation of Chlamydia psittaci isolated from a horse. Veterinary Microbiology 24, 11-19.

Yates, P. S., Storey, C. C., LuSher, M., Morrison, N. \& Richmond, S. J. (1992). Do horses have TWAR too? In Proceedings of the European Society for Chlamydial Research, vol. 2, p. 193. Edited by P.-A. Mardh, M. La Placa \& M. Ward. Uppsala, Sweden.

Zhang, Y.X., Morrison, S. G., Caldwell, H. D. \& Baehr, W. (1989). Cloning and sequence analysis of the major outer membrane protein genes of two Chlamydia psittaci strains. Infection and Immunity 57, 1621-1625. 